\title{
PENGARUH TERAPI KEPUTUSAN PERAWATAN TANPA PASUNG (KPTP) TERHADAP PENURUNAN KEINGINAN KELUARGA MELAKUKAN PEMASUNGAN
}

\author{
Desak Made Ari Dwi Jayanti, Ni Ketut Ayu Mirayanti, Dewa Putu Arwidana, \\ Ni Putu Sandini Permata Utami \\ Sekolah Tinggi IImuKesehatan Wira Medika Bali, Jalan Kecak No 9A Gatotsubroto Timur Denpasar Bali \\ email: djdesak@gmail.com
}

\begin{abstract}
Abstrak
Pemasungan di Indonesia merupakan permasalahan bidang kesehatan jiwa di Indonesia yang menunjukkan pasien gangguan jiwa belum sepenuhnya mendapatkan perlakuan yang baik serta memenuhi hak asasi manusia. Dampak dari pemasungan antara lain pasien dapat mengalami trauma, merasa dibuang, rendahdiri, depresi dan niat bunuh diri. Upaya yang dapat dilakukan untuk mencegah keluarga mengambil keputusan melakukan pemasungan terhadap pasien skizofrenia dengan terapi keluarga yang bertujuan membantu pencegahan tindakan pasung oleh keluarga kepada pasien gangguan jiwa yang dikenal dengan terapi keputusan perawatan tanpa pasung (KPTP). Tujuan penelitian ini adalah pengaruh terapi KPTP terhadap penurunan keinginan keluarga melakukan pemasungan pada pasien skizofrenia.Jenis penelitian praeksperimental dengan menggunakan rancangan One-group pre-post test design. Jumlah sampel sebanyak 11 orang dengan Purposive sampling. Pengumpulan data menggunakan Kuesioner Keputusan Pasung Daulima.Hasil penelitian menunjukkan rerata keinginan keluarga melakukan pemasungan pada pasien skizofrenia sebelum diberikan terapi KPTP sebesar 152.73 termasuk kategori sedang, setelah diberikan terapi KPTP sebesar 89,82 termasuk kategori rendah. Hasil uji dengan Paired $t$ Test diperoleh nilai $p<0,05$ artinya ada pengaruh terapi KPTP terhadap penurunan keinginan keluarga melakukan pemasungan pada pasien skizofrenia. Disaran kepada Puskesmas agar membuat standar operasional prosedurKPTPserta pelaksanaan terapi dapat dilanjutkan pelaksanaaannya untuk keluarga pasien gangguan jiwa yang lain
\end{abstract}

Kata Kunci $\quad$ : terapi keputusan perawatan tanpa pasung; keluarga; pemasungan; skizofrenia

\section{THE EFFECT OF NON-STOCKS DECISION TREATMENT TOWARDS THE DECREASE OF STOCKS DESIRE IN FAMILY}

\begin{abstract}
Stocks in Indonesia are a mental health problem that shows the patient mental disorder that is not fully get good treatment and fulfill human rights. The impact of deprivation include patients may experience trauma, feel discarded, low self-esteem, depression and suicidal intent. Efforts that can be made to prevent families from making decisions to take care of schizophrenic patients with non-stocks family therapies that is aimed to assist the prevention of family action by the family to the psychiatric patient known as non-stocks decision treatment. The purpose of this study was the effect of non-stocks decision treatment to decrease stocks desire in Family. Pre experimental type of study used One-group design pre-post test design. Numbers of samples were 11 people with Purposive sampling. Data collection used Daulima Questionnaire. The result indicates the average desire of families doing stocks in schizophrenia patients before this treatment was 152.73 or including as medium category, and after being given nonstocks treatment is 89.82 or including as low category. Result of test with Paired $t$ Test obtained $p$ value $<0,05$ means influence of non-stoacks treatment towards the decrease of stocks desire family in schizophrenia patient. The Suggestion will be delivered to district health centre to make operational standard of Non-stocks decision treatment procedure and the implementation can be continued to the family to be implemented.
\end{abstract}

Keywords : decision therapy treatment without parasite; family; shelter; schizophrenia 


\section{LATAR BELAKANG}

Pasien gangguan jiwa pada jaman era globalisasi sekarang ini jumlahnya sangat mengalami peningkatan dari tahun ke tahun. Salah satu penyebab bertambahnya pasien gangguan jiwa adalah beban hidup yang semakin berat dialami seseorang (Zainudin, 2014). Salah satu bentuk gangguan kejiwaan yang memiliki tingkat keparahan yang tinggi adalah skizofrenia. Skizofrenia merupakan gangguan jiwa berat yang akan membebani masyarakat sepanjang hidup penderita yang dikarakteristikan dengan disorganisasi pikiran, perasaan dan perilaku (Sinaga, 2012).

Berdasarkan data profil kesehatan Provinsi Bali tahun 2017 diperkirakan jumlah penduduk yang mengalami gangguan jiwa sebanyak 3\% dari 4 juta jumlah penduduk atau sekitar 120.000 orang dimana sekitar 2000 orang diantaranya mengalami gangguan jiwa berat skizofrenia. Berdasarkan Kabupaten, jumlah pasien skizofrenia tertinggi adalah Kabupaten Karangasem sebanyak 421 orang, kedua Kota Denpasar 210 orang dan ketiga Kabupaten Bangli sebanyak 190 orang (Dinkes Provinsi Bali, 2016). Jumlah pasien skizofrenia Kota Denpasar tahun 2017 terbanyak berada di wilayah kerja Puskesmas II Denpasar timur sebanyak 112, kedua di wilayah kerja Puskesmas II Denpasar Selatan sebanyak 37 orang dan ketiga di Wilayah Kerja Puskesmasa I Denpasar Barat sebanyak 35 orang. Data pasien skizofrenia Puskesmas II Denpasar timur diperoleh data bahwa jumlah rata-rata pasien di Wilayah Kerja Puskesmas II Denpasar Timur tahun 2015 sebanyak 80 pasien, tahun 2016 sebanyak 90 pasien, dan tahun 2017 sebanyak 112 pasien yang mengalami skizofrenia, sedangkan jumlah pasien dengan riwayat pernah dipasung dalam 3 tahun terakhir sebanyak 5 dan semuanya sudah dibebaskan (dinas Kesehatan Kota Denpasar, 2017).

Hasil wawancara yang peneliti lakukan dengan 5 orang keluarga yang pernah melakukan pemasungan didapatkan data alasan dilakukan pemasungan adalah karena pasien sering kumat, tidak mau minum obat serta jika dibiarkan bebas di khawatirkan membahayakan dirinya sendiri dan orang laian karena tidak ada yang ada yang memperhatikan di rumah. Sebanyak 3 orang keluarga mengatakan tidak berdayaterhadap tekanan masyarakat sekitar yang merasa terancam dengan perilaku pasien. Padadasarnya keluarga tidak ingin memasung pasien karena merasa sayang kepada anggota keluarganya tersebut, namun tekanan secara psikis dari lingkungan sekitar yang sudahantipati dengan perilaku pasien memaksa keluarga untuk melakukan tindakan pasung. Hasil Riskesdas tahun 2013 menyebutkan kuranglebih 14,8\% pernah dipasung dalam masa hidupnya. Hal ini menunjukan adanya masalah dalam bidang kesehatan jiwa di Indonesia oleh karena itu pemasungan tidak diperkenankan dengan alasan manusiawi (Idaiani dan Raflizar,2015)

Pemasungan di Indonesia merupakan permasalahan bidang kesehatan jiwa di Indonesia yang menunjukkan pasien gangguan jiwa belum sepenuhnya mendapatkan perlakuan yang baik serta memenuhi hak asasi manusia (Depkes RI, 2013). Pasung merupakan tindakan keluarga atau masyarakat terhadap penderita gangguan jiwa (biasanya skizofrenia) dilakukan untuk membatasi gerak penderita gangguan jiwa. Cara pemasungan dibuat secara khusus dengan kayu (kayu apit) pada kedua kaki penderita sehingga orang tersebut tidak dapat berjalan. Penderita bahkan tidak dapat melakukan aktivitas kehidupan dasar seperti perawatan diri, buang air kecil dan buang air besar. Metode pemasungan tidak terbatas pada pemasungan dengan menggunakan kayu atau rantai pada kaki, tetapi juga tindakan pengekangan yang membatasi gerak, pengisolasian dan penelantaran (Idaiani dan Raflizar, 2015). 
Kementerian Kesehatan memperkirakan jumlah Orang Dengan Gangguan Jiwa (ODGJ) tahun 2015 yang mengalami pemasungan di seluruh Indonesia mencapai $14,3 \%$ atau sekirar 57.000 orang pernah atau sedang dipasung, meningkat dibandingkan tahun 2014 mencapai 11,3\% atau sekirar 42.000. Angka pemasungan di pedesaan adalah sebesar 18,2\%. Angka ini lebih tinggi jika dibandingkan dengan angka di perkotaan, yaitu sebesar 10,7\% (Halida dkk, 2015). Hasil Riskesdas tahun 2013 menyebutkan kurang lebih 14,8\% pernah dipasung dalam masa hidupnya. Hal ini menunjukkan adanya masalah dalam bidang kesehatan jiwa dilndonesia oleh karena itu pemasungan tidak diperkenankan dengan alasan manusiawi (Kemenkes RI, 2013).

Data jumlah pasien pasung di Provinsi Bali, berdasarkan data Rumah Sakit Jiwa Provinsi Bali, jumlah warga yang masih dipasung dalam kurun waktu 5 tahun yaitu 2008-2013 mencapai 300 orang lebih. Jumlah ini tersebar di 57 kecamatan di Bali. Jumlah pasien gangguan jiwa yang diketahui dipasung oleh keluarganya tahun 2014 mencapai 30 orang dari seluruh Bali meningkat menjadi 55 orang pada tahun 2015 dan meningkat menjadi 62 orang pada tahun 2016 dan sebanyak 68 orang pada tahun 2017. Maka dari jumlah itu, masih ada beberapa orang dengan gangguan jiwa yang tidak dirawat di rumah sakit karena sebagian keluarga mereka keberatan membawa ke rumah sakit dengan alasan beragam. Sebanyak 14 orang dengan gangguan jiwa yang terpasung itu menjalani perawatan medis di rumah mereka masing-masing (Rumah Sakit Jiwa Provinsi Bali, 2017).

Dampak dari pemasungan antara lain pasien dapat mengalami trauma, dendam kepada keluarga, merasa dibuang, rendah diri, dan putus asa. Lama-lama muncul depresi dan niat bunuh diri (Idaiani dan Raflizar, 2015). Upaya pemerintah melalui Kementerian Kesehatan RI untuk pencegah pemasungan pada ODGJ, dilakukan dengan mencanangkan program Indonesia Bebas
Pasung pada tahun 2014. Namun sampai dengan sekarang (tahun 2016) belum terlihat penanganan yang signifikan dan komprehensif dalam penanganan dini penderita gangguan jiwa. Program Indonesia Bebas Pasung 2014 saat ini direvisi menjadi Program Indonesia Bebas Pasung 2019, sehingga Indonesia dalam menentukan ketercapaian target masih ada 3 tahun lagi atau bahkan lebih cepat karena proses ini masih berlangsung berkesinambungan dengan adanya komitmen dari pemerintah pusat dan pemerintah daerah Provinsi dan Kota/Kabupaten (Lestari, 2014).

Penelitian Lestari (2014) menyebutkan Variabel yang mempunyai hubungan paling kuat terhadap pasung adalah status ekonomi rumah tangga. Faktor ini ditambah dengan ketidaktahuan fasilitas kesehatan dan tempat tinggal yang jauh dari perkotaan. Penelitian Minas dan Diatri (2012), berupa studi deskriptif tentang kasus pasung yang ditemukan di Pulau Samosir Sumatera Utara. Hasil yang dilaporkan dari studi ini menjelaskan bahwa pelanggaran hak asasi manusia yang direpresentasikan dengan pemasungan bukanlah hasil dari ketidak pedulian atau pengabaian oleh keluarga dan komunitas, atau penolakan untuk menerima perawatan kesehatan, tetapi dianggap sebagai bentuk kelalaian pemerintah tentang tanggung jawab mereka untuk menyediakan pelayanan dasar kesehatan jiwa.

Upaya yang dapat dilakukan untuk mencegah keluarga mengambil keputusan melakukan pemasungan terhadap pasien skizofrenia, maka diperlukan suatu terapi yang dapat mengedukasi dan memandu keluarga dalam pengambilan keputusan perawatan tanpa pasung pada pasien skizofrenia khususnya yang kronik dengan perilaku agresif (Keliat, 2015). Salah satu terapi yang dibutuhkan untuk membantu menyelesaikan masalah pasien gangguan jiwa adalah terapi keperawatan, khususnya terapi modalitas keperawatan jiwa. Terapi modalitas keperawatan jiwa terdiri atas terapi individu, keluarga, kelompok, lingkungan, 
somatik yang dalam implementasi di Indonesia difokuskan pada tiga kelompok terapi yaitu terapi individu, kelompok dan keluarga (Stuart, 2016).

Terapi keluarga diberikan untuk menyelesaikan masalah keperawatan jiwa yang dialami keluarga, berdasarkan kepada keyakinan bahwa orang yang diidentifikasi sebagai sakit menunjukkan gejala perilaku yang merupakan akibat dari masalah yang terjadi dalam sistem keluarga (Stuart, 2016). Keluarga merupakan pendukung utama (primary care giver) dalam perawatan pasien skizofrenia yang diharapkan mampu menjadi support group bagi penderita selama menjalani perawatan di rumah. Kesanggupan keluarga mempertahankan dan mendukung kesehatan pasien dapat dilihat dari tugas kesehatan yang dilaksanakan antara lain mengenali masalah kesehatan, membuat keputusan tindakan kesehatan yang tepat, memberikan perawatan pada anggota keluarga yang sakit, menggunakan fasilitas kesehatan yang ada di masyarakat dan menciptakan suasana rumah yang menunjang bagi pasien (Sulistyowati, 2014). Terapi keluarga yang sering diberikan kepada keluarga adalah terapi triangle dan psikoedukasi keluarga. Selain terapi keluarga tersebut adapula terapi keluarga yang dikembangkan oleh Daulima (2014), bertujuan membantu pencegahan tindakan pasung oleh keluarga kepada pasien gangguan jiwa yang dikenal dengan terapi keputusan perawatan tanpa pasung (KPTP).

Terapi KPTP merupak:an terapi jangka pendek untuk memberdayak:an keluarga dalam pengambilan keputusan perawatan yang tepat dan terapeutik tanpa pasung. Prinsip terapi ini adalah mengedukasi keluarga tentang masalah orang dengan gangguan jiwa, stres dan respons terhadap stres yang dialami keluarga, altematif penyelesaian stres dalam keluarga, konsekuensi positif dan negatif dari setiap altematif pilihan, mendorong pengambilan keputusan perawatan yang tepat dan terapeutik tanpa pasung. Terapi
KPTP sehagai alat bantu terapi diherikan hila ditemukan adanya tingkat keputusan pasung yang tinggi pada keluarga pasien gangguan jiwa. Tingkat keputusan pasung ini diukur menggunakan Kuesioner Keputusan Pasung Daulima (KKPD) (Daulima, 2014).

Berdasarkan studi pendahuluan yang dilakukan di wilayah kerja Puskesmas II Denpasar Timur dengan melakukan wawancara dengan 5 orang keluarga yang pernah melakukan pemasungan didapatkan data alasan dilakukan pemasukan sebanyak 2 orang keluarga mengatakan karena pasien sering kumat, tidak mau minum obat serta jika dibiarkan bebas di khawatirkan membahayakan dirinya sendiri dan orang laian karena tidak ada yang ada yang memperhatikan di rumah. Sebanyak 3 orang keluarga mengatakan tidak berdaya terhadap tekanan masyarakat sekitar yang merasa terancam dengan perilaku pasien dan lelah merawat pasien. Pada dasarnya keluarga tidak ingin memasung pasien karena merasa sayang kepada anggota keluarganya tersebut, namun tekanan secara psikis dari lingkungan sekitar yang sudah antipati dengan perilaku pasien memaksa keluarga untuk melakukan tindakan pasung.

Berdasarkan beberapa penelitian diatas, maka peneliti tertarik untuk melakukan penelitian ini menggali lebih dalam tentang pengaruh terapi keputusan perawatan tanpa pasung (KPTP) terhadap penurunan keinginan keluarga melakukan pemasungan pada pasien skizofrenia di Puskesmas II Denpasar Timur. Karena keberadaan seseorang yang mengalami gangguan jiwa dalam keluarganya akan menjadi beban tersendiri bagi keluarganya.

\section{METODE}

Jenis penelitian ini adalah pra experiment yaitu percobaan berupa perlakuan atau intervensi terhadap suatu variabel, dari perlakuan tersebut diharapkan terjadi perubahan. Rancangan dalam penelitian ini menggunakan one-group Pra-test-posttest design. 
Tempat penelitian yang digunakan untuk penelitian ini adalah di Wilayah Kerja Puskesmas II Denpasar Timur pada bulan Juni 2018. Sampel dalam penelitian ini adalah keluarga pasien skizofrenia yang ditentukan berdasarkan kriteria inklusi meliputi keluarga yang bersedia menjadi responden dan bias mengikuti terapi KPTP sebanyak 3 kali, anggota keluarga terdekat yang langsung merawat pasien (care giver) dan tinggal Bersama klien. Jumlah sampel sebanyak 11 orang sampel, tehnik sampling yang digunakan adalah purposive sampling. Variabel independen dalam penelitian ini adalah terapi keputusan perawatan tanpa pasung (KPTP). Variabel dependen dalam penelitian ini adalah penurunan keinginan keluarga melakukan pemasungan pada pasien skizofrenia.

Prosedur analisis dalam penelitian ini proses pengolahan data mengikuti langkah - langkah sebagai berikut editing, coding, entri data dan cleaning atau tabulasi. Analisa data pada penelitian ini menggunakan uji"Paired $t$ Test". Penentuan hipotesis diterima atau ditolak apabila nilai probability lebih kecil dari nilai signifikansi ( $p$ $<0,05)$ maka ada pengaruh terapi keputusan perawatan tanpa pasung (KPTP) terhadap keputusan keluarga melakukan pemasungan pada pasien skizofrenia di Puskesmas II Denpasar Timur.

HASIL

Umur

Tabel 1 Karakteristik responden berdasarkan $\operatorname{umur}(n=11)$

\begin{tabular}{clcc}
\hline No & Umur & $\mathrm{f}$ & $\%$ \\
\hline 1 & $26-35$ th & 2 & 18.2 \\
2 & $36-45$ th & 3 & 27.3 \\
3 & $46-55$ th & 6 & 54.5 \\
\hline & Total & 11 & 100,0 \\
\hline
\end{tabular}

Berdasarkan tabel di atas, menunjukkan bahwa karakteristik responden berdasarkan umur sebagian besar berumur 46-55 tahun yaitu sebanyak 6 orang (54,5\%).
Pendidikan

Tabel 2 Karakteristik responden berdasarkan pendidikan $(n=11)$

\begin{tabular}{clcc}
\hline No & Pendidikan & $\mathrm{f}$ & $\%$ \\
\hline 1 & SD & 1 & 9.1 \\
2 & SMP & 4 & 36.4 \\
3 & SMA & 6 & 54.5 \\
\hline & Total & 11 & 100,0 \\
\hline
\end{tabular}

Berdasarkan tabel di atas, menunjukkan bahwa karakteristik responden berdasarkan pendidikan sebagian besar tamat SMA yaitu sebanyak 6 orang(54,5\%).

Tabel 3 Distribusi keinginan keluarga melakukan pemasungan pada pasien skizofrenia sebelum dan sesudah diberikan terapi KPTP $(\mathrm{n}=11)$

\begin{tabular}{lcccc}
\hline Variabel & rerata & SD & median & Min-mak \\
\hline Pre Test & 152,73 & 22,957 & 166 & $120-176$ \\
Pos Test & 89,82 & 12,073 & 88 & $68-112$ \\
\hline
\end{tabular}

Berdasarkan tabel diatas menunjukkan rerata keinginan keluarga melakukan pemasungan pada pasien skizofrenia sebelum diberikan terapi KPTP sebesar 152.73 termasuk rerata pre-test pemasungan. Terjadi penurunan rerata keinginan keluarga melakukan pemasungan pada pasien skizofrenia setelah diberikan terapi KPTP sebesar 89,82 termasuk kategori rerata pre-test pemasungan.

Tabel 4 Analisa keinginan keluarga melakukan pemasungan pada pasien skizofrenia sebelum dan sesudah diberikan terapi KPTP $(n=11)$

\begin{tabular}{lcccc}
\hline Variabel & Rerata & SD & p value & t hitung \\
\hline Pre Test & 152,73 & 22,957 & 0,000 & 10,971 \\
Pos Test & 89,82 & 12,073 & & \\
\hline
\end{tabular}

Berdasarkan tabel diatas menunjukkan terjadi penurunan rerata keinginan keluarga melakukan pemasungan pada pasien skizofrenia antara pre test dengan post test sebesar 62,909. Hasil uji dengan paired t test diperoleh nilai $p<0,05$ artinya ada perbedaan yang bermakna keinginan keluarga untuk melakukan pemasungan pretest dan post-test hal ini menunjukkan ada 
pengaruhterapi keputusan perawatan tanpa pasung (KPTP) terhadap penurunan keinginan keluarga melakukan pemasungan pada pasien skizofrenia di Puskesmas ॥ Denpasar Timur.

\section{PEMBAHASAN}

Keinginan keluarga melakukan pemasungan pada pasien skizofrenia sebelum diberikan terapi keputusan perawatan tanpa pasung (KPTP)

Hasil penelitian menunjukkan rerata keinginan keluarga melakukan pemasungan pada pasien skizofrenia sebelum diberikan terapi KPTP sebesar 152.73 termasuk kategori sedang. Menurut Syarniah, (2014) penyebab penderita gangguan jiwa berat seperti skizofrenia dilakukan pemasungan adalah karena dampak social berupa penolakan, pengucilan dan diskriminasi. Dampak ekonomi dapat berupa hilangnya hari produktif untuk mencari nafkah bagi pasien maupun keluarga yang harus merawat, tingginya biaya perawatan yang harus ditanggung keluarga maupun masyarakat dan stigma yang menyertai pasien skizofrenia.

Keluarga memiliki keinginan melakukan pemasungan terhadap pasien skizofrenia, menurut Daulima, (2014) banyak alasan yang dijadikan keluarga sehingga mengambil keputusan untuk memasung. Selain alasan keamanan dan stigma masyarakat, kondisi social ekonomi dan kegagalan tindakan alternative prapasung juga membuat keluarga memutuskan untuk memasung keluarganya dengan gangguan jiwa.

Menurut Minas dan Diatri (2012) factor keluarga melakukan pemasungan diantaranya untuk mencegah pasien melakukan tindak kekerasan yang dianggap membahayakan terhadap dirinya atau orang lain. Selain itu upaya untuk mencegah pasien agar tidak kambuh (meninggalkan rumah, perilaku kekerasan, isolasi sosial). Selain itu terdapat factor kemiskinan dan rendahnya pendidikan keluarga merupakan salah satu penyebab pasien gangguan jiwa berat hidup terpasung. Ketidaktahuan pihak keluarga, rasa malu pihak keluarga, penyakit yang tidak kunjung sembuh, tidak adanya biaya pengobatan, dan tindakan keluarga untuk mengamankan lingkungan merupakan penyebab keluarga melakukan pemasungan. Salah satu kendala ekonomi kelurga berpengaruh pada biaya berobat yang harus ditanggung pasien tidak hanya meliputi biaya yang langsung berkaitan dengan pelayanan medic seperti harga obat, jasa konsultasi tetapi juga biaya spesifik lainnya seperti biaya transportasi ke rumah sakit dan biaya akomodasi lainnya.

Hasil penelitian ini didukung oleh hasil penelitian Lestari (2014) tentang kecenderungan atau sikap keluarga penderita gangguan jiwa terhadap tindakan pasung studi kasus di RSJ Amino Gondho Hutomo Semarang. Hasil penelitian menunjukkan sebanyak 39 (48, 8\%) mempunyai sikap kurang mendukung terhadap tindakan pasung yaitu sejumlah 40 (50\%).

Keinginan keluarga untuk melakukan pemasungan pada pasien skizoprenia sebagian besar dalam kategori sedang dapat disebabkan karena keluarga ingin mencegah pasien melakukan tindakan kekerasan baik terhadap anggota keluarga lainnya maupun masyarakat sekitanya. Pasien gangguan jiwa kronis yang cenderung agresif seringkali melakukan tindakan yang membahayakan orang lain dan lingkungan, seperti memukul, merusak fasilitas umum, dan mengamuk. Tindakan ini dapat memicu tindakan pembalasan dari orang lain atau masyarakat sekitar yang terkena dampak dari perilaku agresif pasien.

Menurut asumsi peneliti, pada dasarnya keluarga tidak ingin memasung pasien karena merasa saying kepada anggota keluarganya tersebut, namun tekanan secara psikis dari lingkungan sekitar yang sudah antipasti dengan perilaku pasien memaksa keluarga untuk melakukan 
tindakan pasung. Kondisi ini menimbulkan konflik berat pada keluarga sebelum tindakan pasung dilakukan. Konflik ini terjadi karena pilihan tindakan memasung atau tidak memiliki konsekuensi yang sama beratnya. Dalam hal ini keputusan yang diambil keluarga sebenarnya tidak mudah dan kerap kali membutuhkan proses yang cukup panjang dengan mempertimbangkan segala konsekuensinya.

Keinginan keluarga melakukan pemasungan pada pasien skizofrenia setelah diberikan terapi keputusan perawatan tanpa pasung (KPTP)

Hasil penelitian menunjukkan terjadi penurunan rerata keinginan keluarga melakukan pemasungan pada pasien skizofrenia setelah diberikan terapi KPTP sebesar 89,82 termasuk mean post test. Menurut Keliat (2015) terapi KPTP mampu menurunkan keinginan keluarga melakukan pemasungan, karena pemberian terapi KPTP merupakan terapi yang memberikan edukasi dan memandu keluarga dalam pengambilan keputusan perawatan tanpa pasung pada pasien skizofrenia khususnya yang kronik dengan perilaku agresif.

Menurut Daulima (2014) pemberian terapi KPTP bertujuan memandu keluarga mengambil keputusan secara sistematis dan logis dengan mempertimbangkan berbagai konsekuensi dari setiap alternative pilihan tindakan yang tersedia melalui keputusan perawatan yang tepat dan terapeutik dengan urutan langkah-langkah logis penyelesaian masalah yang disusun secara sistematis dimulai dengan mengidentifikasi stressor akibat memiliki anggota keluarga yang mengalami gangguanjiwa di rumah, dilanjutkan dengan mengidentifikasi stress atau respons terhadap stressor tersebut, kemudian mengidentifikasi konsekuensi dari empat pilihan perawatan yang tersedia untuk menyelesaikan stress akibat memiliki anggota keluarga yang mengalami gangguan jiwa. Langkah berikutnya adalah memilih keputusan yang akan diambil dan akhirnya memutuskan pilihan tersebut sebagai alternative penyelesaian masalah stress dalam keluarga.

Hasil penelitian ini sejalan dengan hasil penelitian Aji (2016) pengaruh pendidikan kesehatan terhadap pengetahuan dan sikap keluarga dan masyarakat yang terdapat pasien pasca pasung di Tawangsari Universitas Muhammadiyah Surakarta. Hasil penelitian menunjukkan terjadi peningkatan pengetahuan setelah dilakukan pendidikan kesehatan dari rata-rata pre test sebesar 1.51 menjadi 1.84 saatpost test. Hasil sikap responden juga terjadi peningkatan dari rata-rata sebesar 50.97 saat pre test menjadi 54.62 saat post test.

Penurunan rerata keinginan keluarga melakukan pemasungan pada pasien skizofrenia setelah diberikan terapi KPTP, hal ini disebabkan keluarga diberikan informasi tentang cara mengurangi stressor akibat merawat pasien dengan cara meningkatkan koping akibat gangguan jiwa yang dapat mengakibatkan masalah pada keluarga. Informasi yang diberikan berdasarkan pada kebutuhan keluarga, keluarga memberikan kesempatan untuk bertanya, bertukar pandangan tentang stresor yang dialami serta mengidentifikasi konsekuensi dari perawatan yang dilakukan. informasi yang diberikan dapat memenuhi kebutuhan keluarga akan informasi tentang perawatan gangguan jiwa. Dorongan keinginan untuk melakukan tindakan ditentukan oleh seberapa banyak informasi alternative pilihan yang diperoleh sebelum tindakan untuk memenuhi kebutuhan tersebut dilakukan. Pada penelitian ini, setelah mengerti konsekuensi dari setiap pilihan perawatan semua keluarga pada akhirnya menyatakan tidak ingin melakukan tindakan pasung terhadap klien dan lebih memilih untuk membawa klien ke pelayanan kesehatan jiwa yaitu puskesmas atau rumah sakit. 
Pengaruh Terapi Keputusan Perawatan Tanpa Pasung (KPTP) terhadap Penurunan Keinginan Keluarga melakukan Pemasungan pada Pasien Skizofrenia

Berdasarkan hasil uji menunjukkan terjadi penurunan rerata keinginan keluarga melakukan pemasungan pada pasien skizofrenia antara pre test dengan post test sebesar 62,909. Hasil uji dengan Paired $t$ Test diperoleh nilai $p<0,05$ artinya ada perbedaan yang bermakna keinginan keluarga untuk melakukan pemasungan pretest dan post-test hal ini menunjukkan ada pengaruh terapi keputusan perawatan tanpa pasung (KPTP) terhadap penurunan keinginan keluarga melakukan pemasungan pada pasien skizofrenia di Puskesmas II Denpasar Timur.

Hasil penelitian ini sesuai dengan teori Daulima (2014) yang mengatakan terapi KPTP dapat membantu keluarga dalam meningkatkan jumlah sumber koping. Kemampuan ini dapat tercapai karena setelah memahami konsekuensi dari setiap pilihan perawatan dan mampu mengambil keputusan yang tepat dan terapeutik keluarga menjadi terkondisi untuk melihat dan menggunakan sumber koping lain sebagai alternatif untuk membantu penyelesaian masalah yaitu perawatan tanpa pasung. Keluarga akan mengalami beban yang lebih berat kalau mereka tidak memiliki sumber koping yang adekuat dan kurangnya dukungan sosial Keluarga yang terlibat dalam penelitian ini pada akhirnya mampu mengambil keputusan perawatan yang tepat dan terapeutik yaitu membawa klien ke unit pelayanan kesehatan jiwa untuk ditangani lebih lanjut setelah diberikan pengetahuan dan kemampuan untuk mengambil keputusan perawatan melalui terapi KPTP.

Terapi KPTP menyebabkan terjadinya penurunan keinginan keluarga melakukan pemasungan pada pasien skizofrenia, menurut Stuat (2016) salah satu terapi yang dibutuhkan untuk membantu menyelesaikan masalah pasien gangguan jiwa adalah terapi keperawatan, khususnya terapi modalitas keperawatan jiwa. Terapi modalitas keperawatan jiwa terdiri atas terapi individu, keluarga, kelompok, lingkungan, somatik yang dalam implementasi di Indonesia difokuskan pada tiga kelompok terapi yaitu terapi individu, kelompok dan keluarga. Terapi keluarga yang dikembangkan oleh Daulima (2014), bertujuan membantu pencegahan tindakan pasung oleh keluarga kepada pasien gangguan jiwa yang dikenal dengan terapi keputusan perawatan tanpa pasung (KPTP).

Penelitian Sari (2014) dengan judul pengaruh family psychoeducation therapy terhadap beban dan kemampuan keluarga dalam merawat pasien pasung di Kabupaten Bireuen Nanggroe Aceh Darussalam. Hasil menunjukkan penurunan beban keluarga dan peningkatan kemampuan keluarga secara bermakna setelah mendapat FPE. Penelitian Aji (2016) tentang pengaruh pendidikan kesehatan terhadap pengetahuan dan sikap keluarga dan masyarakat yang terdapat pasien pasca pasung di Tawangsari Universitas Muhammadiyah Surakarta, hasil analisis menunjukan terdapat pengaruh yang signifikan antara sikap danpengetahuan sebelum dan sesudah diberikan promosi kesehatan dengan Sig. (2-tailed) 0.000.

Peneliti berpendapat, terapi KPTP merupakan salah satu jenis terapi keluarga yang dikembangkan untuk membantu keluarga memutuskan pilihan alternative perawatan tanpa pasung untuk menyelesaikan masalah perawatan klien gangguan jiwa dengan cara berdiskusi untuk menyelesaikan konflik, membantu menurunkan tingkat stresor, respons terhadap stresor, meningkatkan penggunaan sumber koping, menumnkan tingkat keinginan memutuskan tindakan pasung yang pada akhimya menurunkan tingkat keputusan keluarga dalam melakukan tindakan pasung terhadap anggota keluarganya yang mengalami gangguan jiwa. 


\section{KESIMPULAN DAN SARAN}

Rerata keinginan keluarga melakukan pemasungan pada pasien skizofrenia sebelum diberikan terapi KPTP sebesar 152.73 termasuk kategori sedang dan setelah diberikan terapi KPTP sebesar 89,82 termasuk kategori rendah. Hasil uji dengan Paired $t$ Test diperoleh nilai $p<0,05$ artinya ada perbedaan yang bermakna keinginan keluarga untuk melakukan pemasungan pretest dan post-test hal ini menunjukkan ada pengaruhterapi keputusan perawatan tanpa pasung (KPTP) terhadap penurunan keinginan keluarga melakukan pemasungan pada pasien skizofrenia di Puskesmas ॥ Denpasar Timur.

Puskesmas sebaiknya menjadi pelayanan kesehatan tingkat dasar bagi perawatan pasien gangguan jiwa di masyarakat serta mencegah tindakan pemasungan, agar membuat standar operasional prosedur terapi keputusan perawatan tanpa pasung (KPTP) serta pelaksanaan terapi dapat dilanjutkan pelaksanaaannya untuk keluarga pasien gangguan jiwa yang lain. Serta adanya penelitian selanjutknya dengan menggunakan sampel yang homogen.

\section{REFFERENSI}

Aji. 2016. Pengaruh Pendidikan Kesehatan Terhadap Pengetahuan Dan Sikap Keluarga Dan Masyarakat Yang Terdapat Pasien Pasca Pasung Di Tawangsari Universitas Muhammadiyah Surakarta. Jurnal Cakrawala Galuh, Vol. II, No.7

Daulima. N. H. C. 2014. Proses Pengambilan Keputusan Tindakan Pasung OlehKeluarga Terhadap Klien Gangguan Jiwa. Disertasi. Fakultas IImu Keperawatan Program Doktor Keperawatan

DepKes RI. 2013. Riset Kesehatan Dasar 2013. Jakarta :Badan Penelitian dan
Pengembangan Kesehatan Kementrian Kesehatan RI

Dinas Kesehatan Provinsi Bali. 2016. Rekam Medis Dinas KesehatanProvinsi Bali 2016

Dinas Kesehatan Kota Denpasar. 2017. Rekam Medis Dinas Kesehatan Kota Denpasar 2017

Profil Kesehatan Provinsi Bali. 2017. Data ProfilDinasKesehatanProvinsi Bali

Halida, Dewi, Rasni. 2015. Pengalaman Keluarga dalam Pemenuhan Kebutuhan Perawatan Diri pada Orang Dengan Gangguan Jiwa (ODGJ) dengan Pasung di Kecamatan Ambulu Kabupaten Jember. Skripsi Program Studi IImu Keperawatan Universitas Jember.

Idaiani dan Raflizar. 2015. Faktor yang Paling Dominan terhadap Pemasungan Orangdengan Gangguan Jiwa di Indonesia. Tesis.Pusat Teknologi Terapan Kesehatan dan Epidemiologi Klinik. Badan Litbang Kesehatan. Kemenkes RI.

Keliat. B.A. 2015. Peran serta Keluarga dalam Perawatan Klien GangguanJiwa. Jakarta. EGC

Kementerian Kesehatan RI. 2013. Menuju Indonesia Bebas Pasung. Jakarta: Pusat Komunikasi Publik,Sekretariat Jenderal Kementerian Kesehatan RI.(online):http://www.depkes.go.id/index .php/berita/press-release/1242-menujuindonesia. Diakses tanggal 29 Februari 2018

Lestari. 2014. Kecenderungan Atau Sikap Keluarga Penderita Gangguan Jiwa Terhadap Tindakan PasungStudi Kasus di RSJ Amino Gondho Hutomo Semarang. Skripsi. Program Studillmu Keperawatan STIKES Ngudi Waluyo.

Minas dan Diatri. 2012. Pasung: Physical Restraint and Confinement of The Mentally III in The Community. (online), http://creativecommons.org. Diaksestanggal 19 Pebruari 2018. 
RumahSakit Jiwa Provinsi Bali. 2017. Ekam Medis Rumah Sakit Jiwa Provinsi Bali 2017

Sari. 2014. Pengaruh Family Psychoeducation Therapy Terhadap Beban Dan Kemampuan Keluarga Dalam Merawat Pasien Pasung di Kabupaten Bireuen Nanggroe Aceh Darussalam.Tesis Fakultas IImu Keperawatan Universitas Indonesia.

Sinaga.2012. . Budaya Pasung dan Dampak Yurudis Sosiologis (Studi Tentang Upaya Pelepasan Pasung dan Pencegahan Tindakan Pemasungan di Kabbupaten Wonogiri). IJMS- Indonesia Journal on Medical Science- Volume 1 no 2. .
Stuart. 2016. Prinsip dan Praktik Keperawatan Kesehatan Jiwa. Edisi Indonesia. Jakarta : EGC

Syarniah. 2014. Studi Deskriptif Persepsi Masyarakat Tentang Pasung Pada Klien Gangguan Jiwa Berdasarkan Karakteristik Demografi Di Desa Sungai Arpat Kecamatan Karang Intan Kabupaten Banjar.Skripsi.Jurnal Skala Kesehatan Volume 5 No. 2 Tahun 2014

Zainudin, 2014. Pendekatan Holistik Pada Gangguan Jiwa Skizofrenia. Jakarta: Balai Penerbit FKUI 